\title{
Pseudo Phase Plane and Fractional Calculus modeling of western global economic downturn
}

\author{
J.A. Tenreiro Machado, Maria Eugénia Mata
}

\begin{abstract}
This paper applies Pseudo Phase Plane (PPP) and Fractional Calculus (FC) mathematical tools for modeling world economies. A challenging global rivalry among the largest inter- national economies began in the early $1970 \mathrm{~s}$, when the post-war prosperity declined. It went on, up to now. If some worrying threatens may exist actually in terms of possible ambitious military aggression, invasion, or hegemony, countries' PPP relative positions can tell something on the current global peaceful equilibrium. A global political downturn of the USA on global hegemony in favor of Asian partners is possible, but can still be not accomplished in the next decades. If the 1973 oil chock has represented the beginning of a long-run recession, the PPP analysis of the last four decades (1972-2012) does not con- clude for other partners' global dominance (Russian, Brazil, Japan, and Germany) in reach- ing high degrees of similarity with the most developed world countries. The synergies of the proposed mathematical tools lead to a better understanding of the dynamics underly-ing world economies and point towards the estimation of future states based on the mem- ory of each time series.
\end{abstract}

\section{Keywords}

Pseudo Phase Plane, System modeling, Economy, Fractional Calculus

\section{Introduction}

This last 2007-2008 crisis was very severe, and many countries still drag on its consequences, suffering from high unemployment rates, sluggish economic recovery, and banking financial distress [1]. As far as those difficulties translated into social unrest and migration movements in the world scene, poor expectations among some analysts led them to inquire on the capacity to overcome these difficulties. Pessimistic views even question the Western world ability to preserve global hegemony [2], and frequently tell on an acceleration of convergence. From this perspective, Fogel 2007 presents the possibility of a real threat of a global geopolitical turnover by 2040. The relative weight of the USA GDP on the world GDP will decline from $22 \%$ to about $14 \%$. In the same way, the relative weight of the European GDP on the world GDP will decline from $21 \%$ to about $5 \%$. A successful convergence of Asian partners with core countries will make democracy depend on those Asian partners.

Europe and the United States of America are now much more optimistic in what respects GDP growth for the next years. However, economic historians have compared nowadays indicators with past crises indicators, and concluded that the current crisis has a new scale in comparison with past crises: In the (UK, for example) the "banking system has faced episodes of instability at various points throughout the past two centuries", but crises in the nineteenth century were much less severe 
as "instability increases significantly in the second half of the twentieth century, which is consistent with the idea that the frequency of financial instability has increased in this period" [3-6].

Of course crises are normal episodes. Capitalism is a flexible self-regulated system made of prosperity and crisis [7]. If prosperity and bubbles create crises and depressions, crises and depressions always have given place to new prosperity [8]. The end of capitalism prophecy based on Marxian views never materialized [9]. Capitalism resilience for survival results from business cycles that alternate prosperity and crisis.

At the same time, convergence is a well-studied issue, and deserves the humankind approval, for improving the lowest conditions of life on the face of the planet, contributing for global welfare and happiness. In 1960 the economic historian Walter Rostow analyzed the available evidence on convergence, and considered the different moments when industrialization took off in the past, for the different 1960s industrialized countries [9]. According to him, a common path exists for each country after the industrialization take-off. Investment and new technologies leads any industrialization process to maturation, and each one of these partners would get a steady-state phase of large and generalized mass consumption patterns. Seventy years were enough to close the distance from take-off to a steady state mass consumption.

The Multi-dimensional scaling method was applied to the analysis of economic growth have proved that convergence stands mainly among European partners, some European offshores (Canada, USA, and Australia), and Japan [10,11]. Asian partners such as India and China still remain far from a convergence with core countries.

In this paper these questions are approached in using Pseudo Phase Plane (PPP) and Fractional Calculus (FC) tools to discuss the global dynamics of the world system and convergence of ten major countries, in order to check both views. The PPP method allows the study of the dynamics of time series while avoiding the numerical calculation of derivatives. On the other hand, FC is a mathematical tool that embeds the modeling of phenomena with long term memory effects. Therefore, the common adoption of the two methodologies allows not only a direct visualization and interpretation of the dynamics of country economies, but also the formulation of schemes for estimating the future evolution of the time series. The ten selected major global partners are the European UK, Germany, and Russia, the Asian China, India, and Japan, and the American USA and Brazil. Having these ideas in mind, the paper is organized as follows. Section 2 presents the fundamentals of pseudo phase space representation and fractional operators. Section 3 is devoted to methodology and analytical aspects of economic dynamics. Section 4 presents the estimations and discusses their accuracy. Finally, Section 5 outlines the main conclusions.

\section{Preliminary concepts}

This section introduces the main concepts that motivate this study. Section 2.1 describes the PPP method and Section 2.2 presents the fundamentals of FC.

\subsection{Pseudo Phase Plane}

The Pseudo Phase Space (PPS) is a technique useful for analysing systems with complex dynamics where complete information about all states is not available. In comparison with the classical phase space method, the PPS method is more robust to signal noise and allows the representation in a higher dimensional space by using a small sample of measurements of the system time history. The PPS reconstruction is based on Takens' embedding theorem [12]. If a signalaxpt is one component of an attractor that can be represented by a smooth $d$-dimensional manifold, then the topological properties of the time series are equivalent to those of the embedding formed by the $n$-dimensional vectors:

$$
v(t)=[x(t) x(t+\tau) x(t+2 \tau) \cdots x[t+(n-1) \tau]]
$$

where $n>2 d \mathrm{p} 1 ; d ; n 2 \mathrm{~N}$ and $s>0$. The parameters and $n$ denote the time delay and the embedding dimension, respectively. The vector $v$ ठtP is often depicted in a $n$-dimensional PPS graph that depends on the values of $s$ and $n$. Usually, it is adopted $n 1 / 42$ or $n^{1 / 4} 3$ since they allow a direct visualization and interpretation.

In the case of $n 1 / 42$ the PPS degenerates into the PPP. Therefore, the PPP vector $k x \partial t \mathrm{p} x \partial t \mathrm{p} s \mathrm{p}]$ is related to the classical phase plane vector $[2 x \partial t \mathrm{p} x \partial t \mathrm{p}]$ and allows the study of the system dynamics.

An important aspect of the PPP and PPS methods consists of the calculation of the time delay s. Let us adopt a practical point of view and consider that the signal $x ð t \mathrm{P}$ is not extremely noisy. If we have a small value of $s$, then the series $x ठ t \mathrm{P}$ and $x \partial t \mathrm{p} s \mathrm{P}$ are very close (they do not provide two independent coordinates) and we get simply a $45^{\circ}$ line in the PPP chart. On the other hand, if $s$ is very large, then the two series are almost independent (yielding unrelated coordinates), but the common intersection of pairs of values vanishes. In fact, the larger the value of $n$ the smaller the intersection since for a time series of finite length $L$ the intersection has length $L-\partial n-1$ PS. Therefore, some practical compromise is needed for choosing the "optimal" time delay, $\boldsymbol{S}_{m}$ that minimizes some kind of index Jkv $\left.\boldsymbol{v} t \mathrm{p}\right]$ :

$$
\min _{\tau}\{J[v(t)]\}
$$


A common method for choosing $J$ is the autocorrelation function, where $x \partial t \mathrm{p}$ is correlated with $x \partial t \mathbf{p} s p$ for successive values of $s$. The first relative minimum is used for obtaining $s_{m}$. The mutual information and the fractal dimension have also been used when autocorrelation reveals difficulties. It is not established which method is superior and we can have multiple sources of limitations such as difficulty of calculation, lack of precision, low sensitivity, noisy variation of $s$, or sensitivity to finite length $L$ [13-17].

\subsection{Fractional Calculus}

FC generalizes the concept of derivative $D^{\text {lq }}$ to orders $a \mathbb{R}$ [18-22]. In the last years FC was recognized as an useful modeling tool [23-32], and considerable research efforts are being devoted towards extending its application in new areas [33-36]. A particular attention should be paid to the recent emergence of FC in the modeling of phenomena in finance [37-39,13] and economy [40].

The most commonly used definitions of fractional derivatives (FD) are the Riemann-Liouville, the Caputo and the Grünwald-Letnikov (GL) formulations [41]. The GL definition may be written as:

$$
\begin{aligned}
& { }_{a} \mathcal{D}_{t}^{\alpha} x(t)=\lim _{h \rightarrow 0^{+}} \frac{1}{h^{\alpha}} \sum_{k=0}^{\left[\frac{[--\alpha]}{n}\right]} \gamma(\alpha, k) x(t-k h), \quad t>a, \alpha>0 \\
& \gamma(\alpha, k)=(-1)^{k} \frac{\Gamma(\alpha+1)}{k ! \Gamma(\alpha-k+1)}
\end{aligned}
$$

where C C.P is Euler's gamma function, $k \cdot]$ means the integer part of the argument, and $h$ is the step time increment.

FD capture the historical evolution of events and, consequently, fractional systems embed the memory of the system dynamics. This property leads to compact fractional models, while classical integer models often require complex expressions.

In numerical calculations (1) is approximated by truncating the series up to $r$ terms and by substituting the time increment $h$ by the sampling period $T$ yielding:

$$
\mathcal{D}^{\alpha}[x(t)] \approx \frac{1}{T^{\alpha}} \sum_{k=0}^{r} \gamma(\alpha, k) x(t-k T)
$$

Other techniques adopt the Laplace or the $\mathbf{Z}$ transforms and lead to rational fractions [24,42-44].

In the sequel we shall adopt (4) for the approximate calculation of FD. In fact, expression (4) is not only straightforward to apply in time series analysis, but also reveals good robustness in what concerns series truncation and loss of significance due to round-off number representation.

\section{Description of economy dynamics}

In this section we study the dynamical evolution of a setS of 10 large countries during the years 1973-2012. The countries consist of Brazil (BRA), China (CHN), Germany (DEU), France (FRA), Great Britain (GBR), India (IND), Italy (ITA), Japan (JPN), Russia (RUS) and United States (USA). The economy is measured by means of the Gross Domestic Product (GDP) per capita. Data was collected from the World Bank and, in the sequel we shall denote, the time series by $x$ đ

A classical method for analysing the dynamics of nonlinear systems consists of the phase space. However, experimental data has some volatility which precludes the use of high dimensional spaces, because we get larger levels of noise, the higher the order of the derivative. Therefore, often researchers restrict to two-dimensional representations, denoted as Phase Plane (PP). For example, Fig. 1 shows the time evolution of the USA GDP and the corresponding PP, where the first order derivative is simply the difference between two consecutive values, $\left.{ }^{1} \emptyset \mathbb{Z}_{2} \partial \mathrm{P}\right] x$ to $\mathrm{P} * t 0-1 \mathrm{P}$.

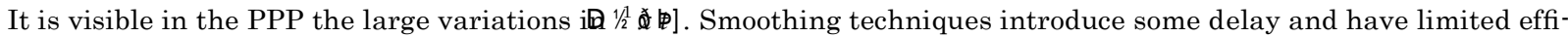

ciency [45]. Therefore, as mentioned in Section 2, the adoption of PPP becomes a relevant tool to overcome these problems.

Another limitation consists of the large sampling period, that in this area is taken yearly, and the limited length of the time series. In order to have a small sampling period while avoiding introducing numerical artefacts without real meaning, it was decided to consider an half-year linear interpolation. This scheme is consistent with the type of time evolution, without large variations between consecutive years, and allows passing from $L 1 / 440$ up to $L 1 / 479$ samples per series.

In spite of volatility, the successful American economic growth in the twentieth century is proved in Fig. 1. The prosperity after the two world wars consolidated the USA hegemony over the world. The American financial market never closed for extended periods, there was no major nationalization affecting large sectors of this economy, and there were no significant social events affecting the nation. (On the contrary, in the previous century there were the 1812-15 War with the British empire and the major Civil War from 1861 to 1865, which brought vast devastation to some important regions of that country, and these events may explain that, extending the time series to include these previous 100 years, the observed values would be much more unstable). 

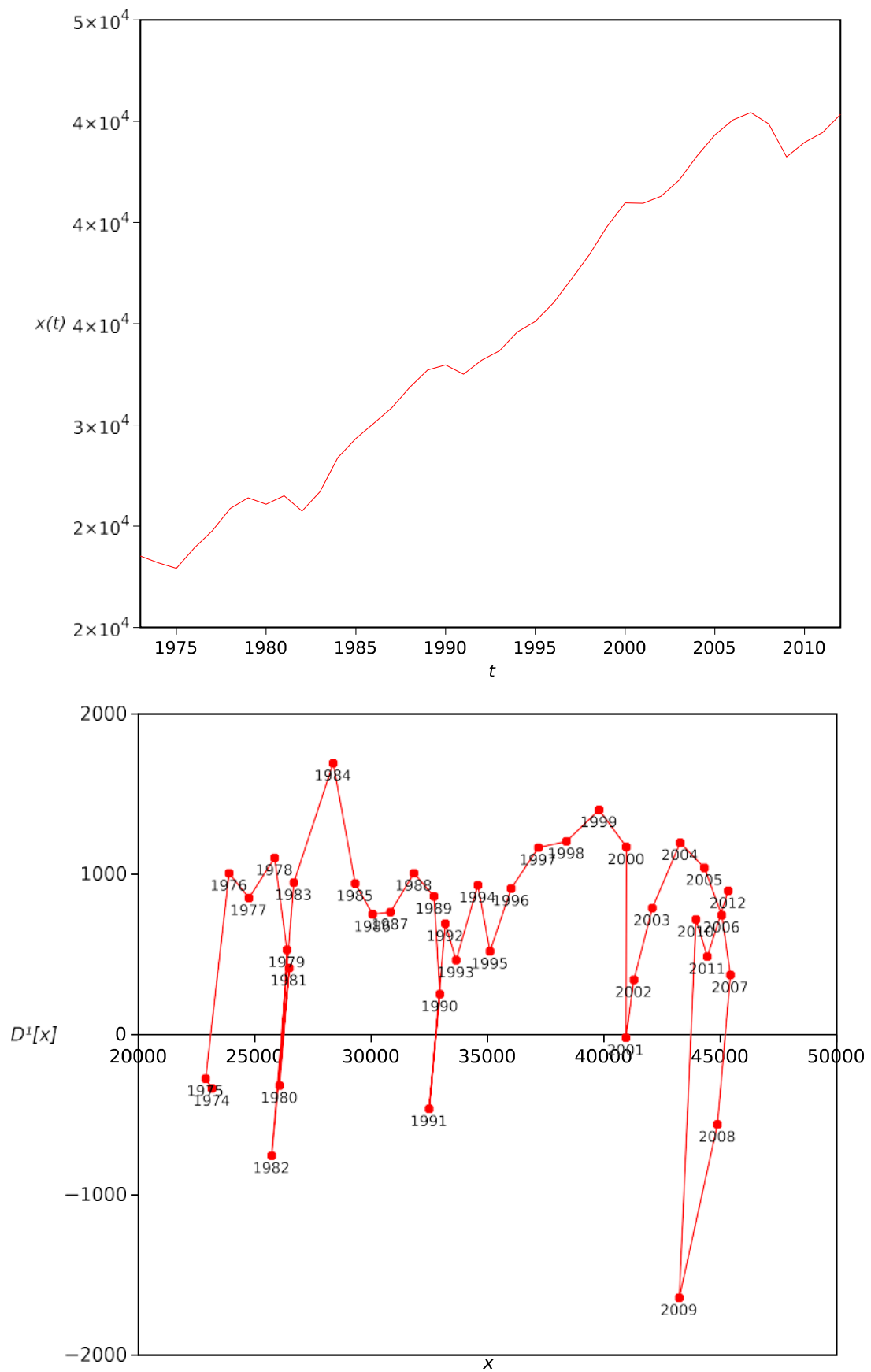

Fig. 1. GDP per capita of USA during 1973-2012: time evolution and PP.

The two oil shocks of 1974-75 and 1982, and the recent 2008-09 sub-prime collapse were the most dramatic periods that interrupted all good trends. Because of contagion effects, they also became global financial downturns. The 2009 deepness evokes the Great Depression of 1929-33. It reveals the housing sector insolvency, and their consequences on unemployment and banking defaults. However, central banking monetary expansion policies and banking bailouts could lessen the effects of the crisis and recover the economic growth.

For comparing series and to calculate $s_{m}$ it was chosen the cosine correlation [46] defined as: 


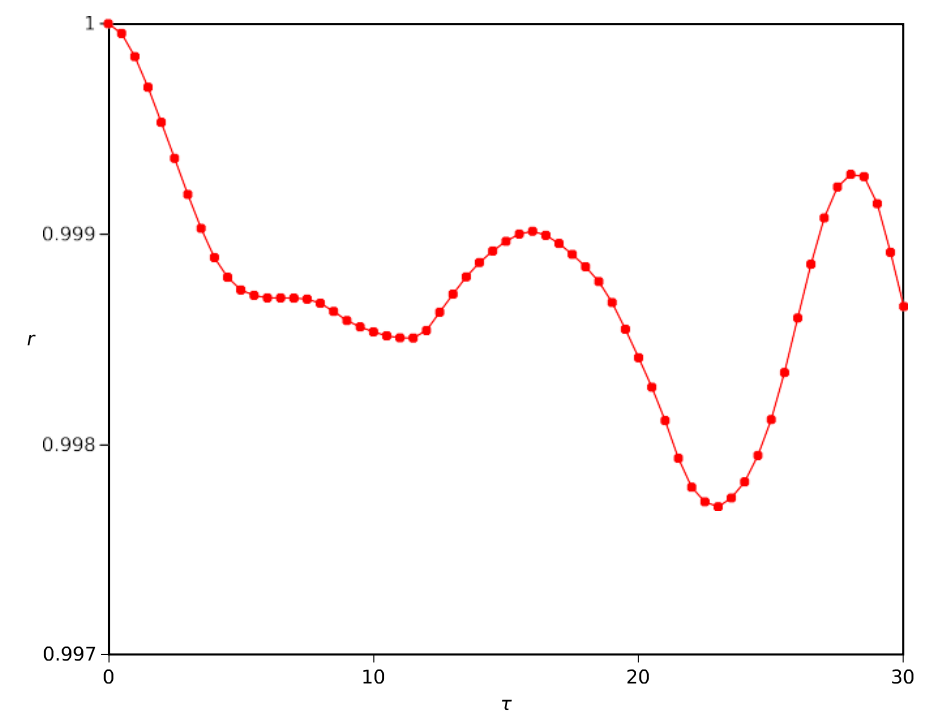

Fig. 2. Variation of the cosine correlation $r$ versus $S$ for the GDP per capita of USA during 1973-2012.

$$
r(\tau)=\frac{\sum_{t-1}^{L-\tau} x(t) x(t+\tau)}{\sqrt{\sum_{t-1}^{L-\tau} x^{2}(t) \sum_{t-1}^{L-\tau} x^{2}(t+\tau)}}
$$

This index is insensitive to the amplitude of $x$ and leads to correct measures even for series with small length. Several numerical experiments with the data confirmed its superior performance over Pearson correlation, Kendall tau rank correlation, and mutual information.

Fig. 2 shows, for example, the variation of $r$ sठ Por the USA GDP with half-year sampling.

PPP and FD are different tools that apparently address distinct topics. However, there is a common background, since both capture the memory of past dynamics for yielding a result. By other words, PPP address memory by means of delay $S_{m}$ in $(2)$ while FD embeds past events in (4) by means of multiple signal samples $k T ; k 1 / 41 ; \ldots ; r$. Therefore, we can conceive some heuristic scheme establishing a relationship between the two methods. In other words, for comparing $\mathrm{D}^{a}$ with $S_{m}$, we need to define a single "figure of merit" or average, $\mathcal{C}_{a v}$, that represents the series of samples. However, the arithmetic mean poses problems due to the slow convergence of $c ; k$.For a list of non-negative real numbers, the geometric mean is smaller than, or equal to, the arithmetic mean. Numerical experiments revealed that the geometric mean leads to a good numerical convergence and, therefore, in the sequel it is adopted for obtaining $c_{a v}$. Having these ideas in mind, we concentrate the successive signal samples of (4) into a signal delayed sample by means of the geometric average of the terms $k 1 / 41 ; \ldots ; r$ resulting in the Z-transform domain:

$$
\gamma_{a v}(\alpha, r) z^{-\tau_{m}}=\left(\prod_{k=1}^{r} \gamma(\alpha, k)\right)^{\frac{1}{t}} z^{\frac{\pi r+17}{2}}
$$

Expression (6) leads directly to $S_{m} 1 / 4 \frac{r o r b 1 p}{2}$, while $c_{a v}$ varies with $a$ and $r$ as depicted in Fig. 3.

For characterizing the geometric average of the GL series (6) it is adopted its maximum value max $\stackrel{(}{\mathcal{C}_{a v}}$ in the range $06 a 61$, as shown in Fig. 4, that determines the corresponding value of $a$.

Table 1 depicts the values of $s_{m}$ and $a$ for the set $S$ of 10 countries.

Having established the values of $s_{m}$ of each time series is now possible to plot the corresponding PPP. Due to the large number of charts it was decided to adopt a single portrait including all traces. On one hand, this methodology embeds all information into a single chart, allowing a simpler comparison and a more compact use of space. On the other hand, details in each chart become less visible, either due to superposition of traces, or to a large variation of limit values for distinct countries. Fig. 5 shows the PPP $k x x^{p} x \partial t \mathrm{p}$ SP] of the GDP per capita for set S of countries during the years $1973-2012$ (with log-log scales). For comparison Fig. 6 shows the PPP scales) where details are more clear. We verify the emergence of three clusters composed by the countries $\mathrm{S}_{1}=\{\mathrm{CHN}, \mathrm{IND}\}$ at the lower left corner, ${ }_{2} \subseteq\{\mathrm{BRA}, \mathrm{RUS}\}$ in the middle zone and $\left.{ }_{3}=\$ \mathrm{DEU}, \mathrm{FRA}, \mathrm{GBR}, \mathrm{ITA}, \mathrm{JPN}, \mathrm{USA}\right\}$ in the top right corner. There is an obvious similarity with a $45^{\circ}$ straight line since economies do not change abruptly and, in general, there are only limited percentage changes per year. Furthermore, traces tend to be over that diagonal since recent values are higher than older ones, representing some global economic progress. A second aspect is the position of clusters and the form of their PPP. In fact, $S_{1}$ represents economies with a fast and steady increase, $S_{2}$ corresponds to countries with 


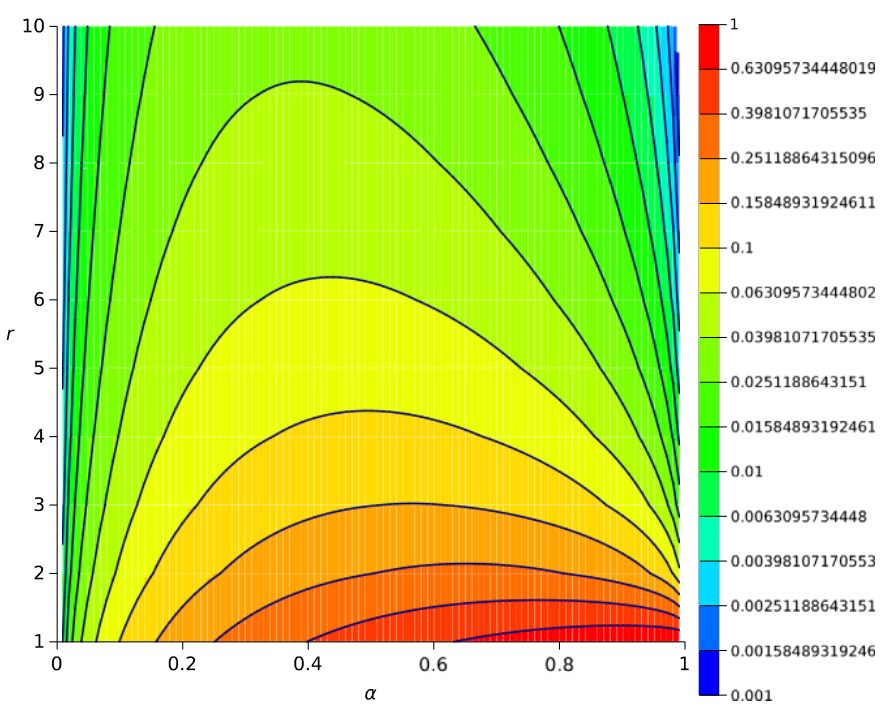

Fig. 3. Locus of $c_{a v}$ versus ð $a ; r \mathrm{P}$.

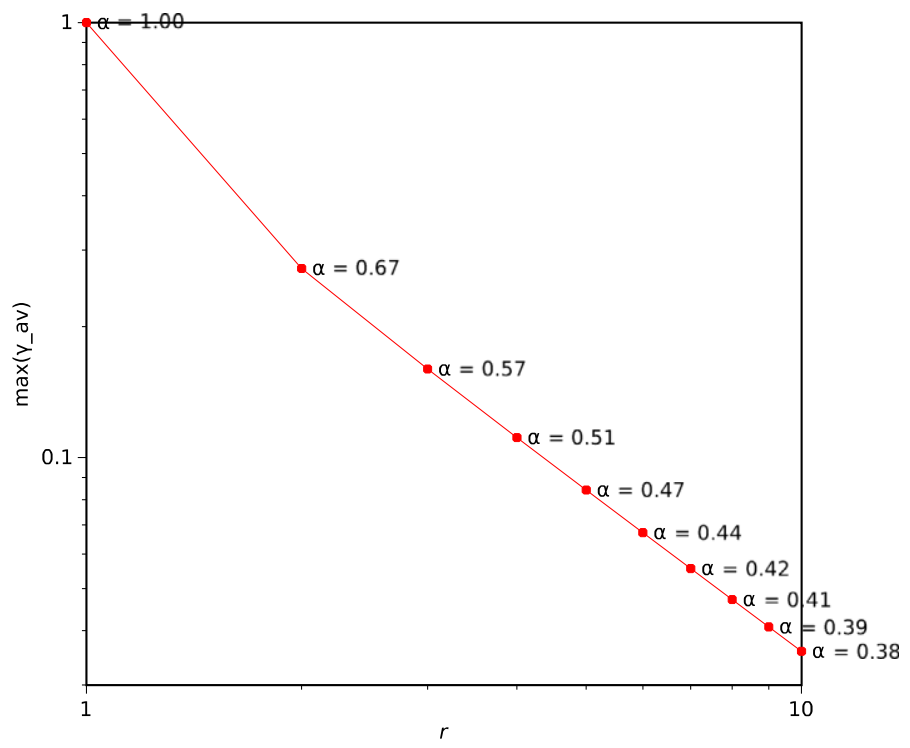

Fig. 4. Locus of $\max { }^{C}{ }_{C_{a v}} /$ versus $r$.

Table 1

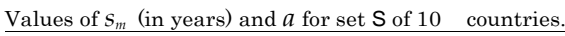

\begin{tabular}{lllllllll}
\hline & BRA & CHN & DEU & FRA & GBR & IND & ITA & JPN \\
\hline$s_{m}$ (years) & 6.5 & 8 & 17.5 & 10.5 & 8 & 18.5 & 21 & 17.5 \\
$a$ & 0.486 & 0.465 & 0.411 & 0.44 & 0.465 & 0.408 & 0.397 & 0.411 \\
\hline
\end{tabular}

variations in the economical cycles, namely both with progress and recession, andS for countries with a smaller but sustained growth.

The paper departs from the G6 partners (United Kingdom, France, Germany, Italy, United States, Japan) and considers the new 4 BRICs (India, China, Russia, and Brazil). The PPP analysis proves that long-term barriers to economic growth are being canceled. In the process of technology diffusion and capitalism extension to all over the world, cultural differences, genetic specificity, or climatic influences are being blurred. 


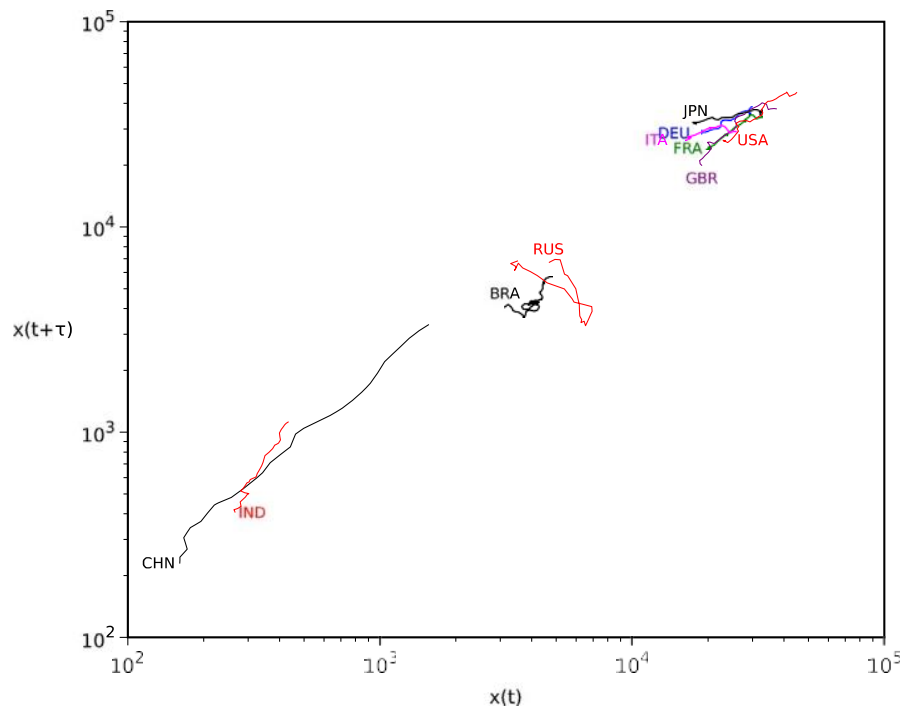

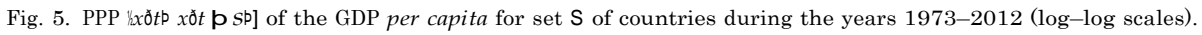

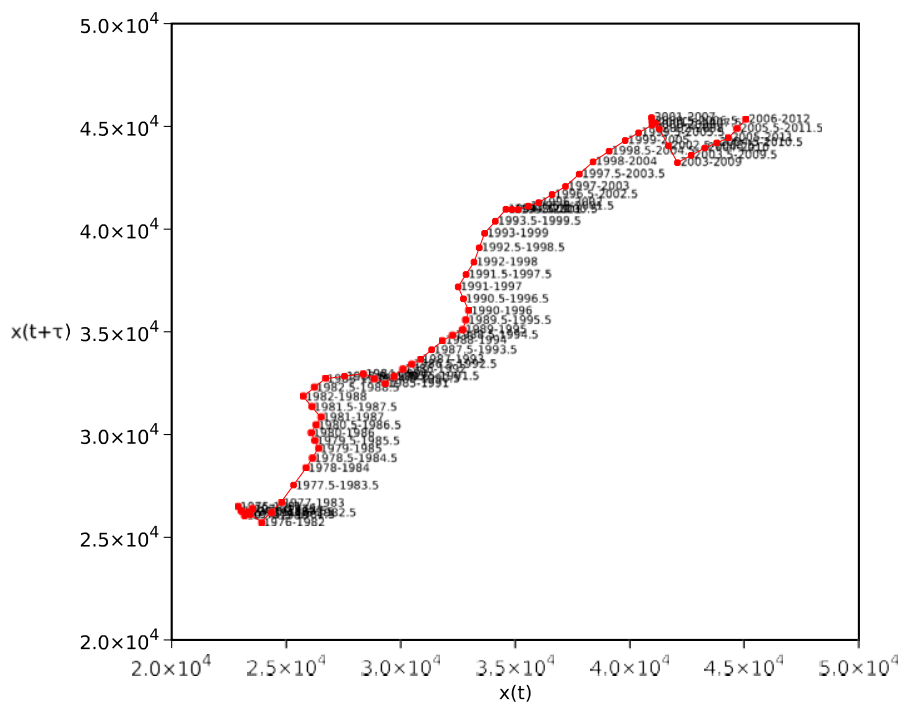

Fig. 6. PPP $\llbracket x \partial t \mathrm{p} x \partial t \mathrm{p} \mathrm{SP]}$ of the GDP per capita for USA during the years 1973-2012 (lin-lin scales).

Fig. 5 is particularly interesting in describing three models of economic growth among large global partners:

- BRICs classified into a sub-group made of the two old Asian civilizations, of China and India, proceed at a fast and steady growth rate pattern; Chinese and Indian comparative disadvantage sectors seem to be catching up "disproportionately faster to the world productivity frontier" [47]. However, there is a Chinese slowdown to 7\% projected growth.

- Other BRICS, Brazil and Russia, exhibit a more erratic growth behavior, made of periods of large growth separated by recurring severe recessions; the Russian unsustainable fiscal deficit and the Brazilian dualism have plagued the transition of these partners from emerging to developed countries.

- The old industrialized countries, including the European pioneers, the USA and Japan, move at slow but steady growth rates.

Standard PPP charts require the calculation of $s_{m}$, but do not yield directly information about the memory of the time series. Nevertheless, it was established previously an heuristic relationship between $s_{m}$ and the fractional order $a$ of the economy dynamics. Having this idea in mind, it was decided to expand the PPP locus by including the information accessing 


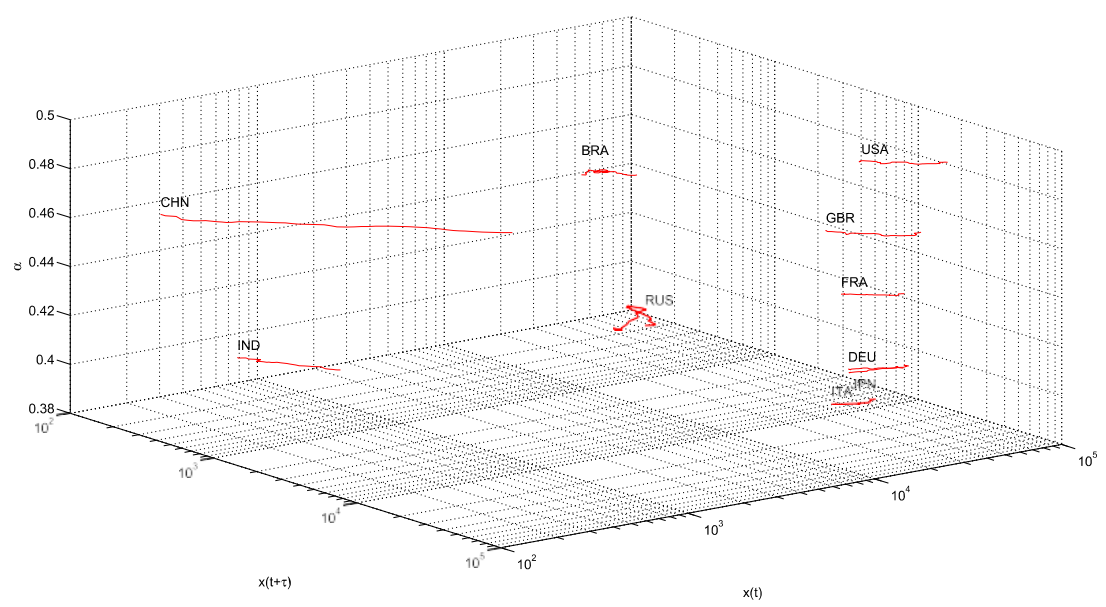

Fig. 7. Locus $k x ð t p x \partial t \mathrm{p} S \mathrm{P} a]$ of the GDP per capita for set $\mathrm{S}$ of countries during the years 1973-2012.

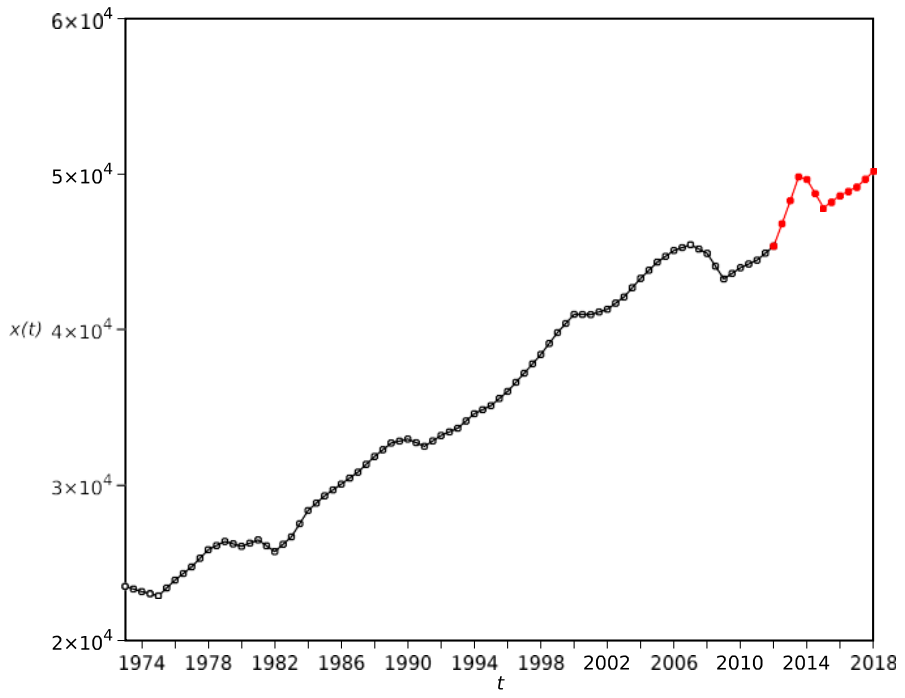

Fig. 8. Time evolution of GDP per capita of USA: Real data during 1973-2012 and estimation during 2012.5-2018.

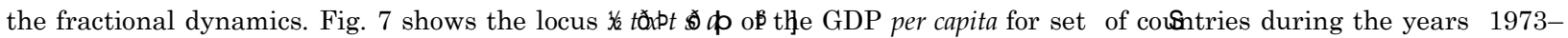
2012. This 3 -dimensional representation extends the standard 2 -dimensional PP portrait $(x$ - and $y$-axes), by including the variable $a$ in the $z$-axis. Besides a more clear visualization, we observe economies with slow dynamics (low values of $a$ ) in the bottom, such as CHN, BRA and USA, and economies with a fast dynamics (high values of $a$ ) in the top, such as IND, RUS, and ITA.

\section{Estimation}

In this section we propose a new method for predicting future values of the GDP per capita based on the PPP.

Once having defined the $S_{m}$ for each country and the corresponding PPP, we observe that there is an "alignment mismatch" between the data series of $x \Varangle$ and $x \approx \mathrm{g}$.PFor standard PPP analysis this effect is negative, particularly for short series, since it reduces the total length of intersection between the two sets. Nevertheless, we can take advantage of it in our case, by foreseeing future, based on past values. Therefore, future values $k x \partial \mathbf{p} 1 \mathrm{p} \cdots x \partial \mathrm{p} s \mathrm{p}]$ are estimated from $k x \partial L p 1-s p \cdots x \partial L P]$ by means of index (5). By other words, we estimate values that maximize (5) for thx $x$ p $1 p \cdots x \partial L \mathbf{p} s p ; x \partial L \mathbf{p} 1-s p \cdots x \partial L P]$.

Fig. 8 shows the time evolution of GDP per capita of USA. Expression (5) leads to $S_{m} 1 / 46$ years, so we have real data during 1973-2012 and estimation during 2012.5-2018. Therefore, the estimation horizon depends on $S_{m}$ and it is distinct for each 
Table 2

Estimation of GDP per capita for set S of 10 countries.

\begin{tabular}{|c|c|c|c|c|c|c|c|c|c|c|}
\hline Year & BRA & $\mathrm{CHN}$ & DEU & FRA & GBR & IND & ITA & JPN & RUS & USA \\
\hline 2012 & 5721.2 & 3348.0 & 38219.8 & 34239.8 & 37608.9 & 1123.2 & 29012.7 & 36942.2 & 6834.0 & 45335.9 \\
\hline 2012.5 & 5526.1 & 3413.5 & 39251.8 & 34939.4 & 38511.3 & 1080.0 & 29969.0 & 38178.0 & 6282.2 & 46771.8 \\
\hline 2013 & 5470.5 & 3586.1 & 40311.7 & 35653.2 & 39435.4 & 1038.4 & 30956.9 & 39455.2 & 5775.0 & 48253.1 \\
\hline 2013.5 & 5605.4 & 3802.5 & 40717.6 & 36381.7 & 40381.7 & 1014.1 & 31977.2 & 40775.1 & 5308.7 & 49781.4 \\
\hline 2014 & 5723.1 & 4019.0 & 41041.0 & 37125.0 & 41350.6 & 1042.7 & 33031.3 & 42139.1 & 4880.0 & 49613.4 \\
\hline 2014.5 & 5840.8 & 4292.4 & 41364.4 & 37883.6 & 42342.8 & 1071.3 & 34120.0 & 43548.8 & 4569.8 & 48707.7 \\
\hline 2015 & 5805.2 & 4565.8 & 41746.3 & 38657.6 & 43358.9 & 1083.2 & 35244.7 & 45005.7 & 4685.8 & 47802.1 \\
\hline 2015.5 & 5769.7 & 4772.2 & 42128.1 & 39085.3 & 44399.3 & 1095.2 & 36406.4 & 45528.1 & 4869.0 & 48199.0 \\
\hline 2016 & 5959.7 & 4978.5 & 42508.4 & 39428.3 & 45464.7 & 1119.0 & 37522.0 & 45439.6 & 5052.1 & 48595.9 \\
\hline 2016.5 & 6149.7 & 5194.0 & 42888.7 & 39771.4 & 44781.0 & 1142.9 & 37729.5 & 45351.2 & 5247.5 & 48865.1 \\
\hline 2017 & 6206.1 & 5409.6 & 43514.5 & 40100.4 & 43424.9 & 1183.0 & 37937.1 & 45822.9 & 5442.8 & 49134.3 \\
\hline 2017.5 & 6262.4 & 5676.5 & 44140.2 & 40429.5 & 43606.1 & 1223.1 & 38280.8 & 46294.6 & 5630.5 & 49630.0 \\
\hline 2018 & 6262.4 & 5943.4 & 44436.8 & 40300.7 & 43787.4 & 1236.1 & 38624.6 & 46325.9 & 5818.2 & 50125.6 \\
\hline 2018.5 & 6262.4 & 6204.2 & 44733.3 & 40171.9 & 43852.8 & 1249.0 & 38898.6 & 46357.2 & 6069.7 & \\
\hline 2019 & & 6465.1 & 44698.1 & 39440.0 & 43918.3 & 1268.5 & 39172.6 & 46370.4 & 6321.3 & \\
\hline 2019.5 & & 6700.3 & 44662.7 & 38708.1 & 43851.4 & 1288.0 & 39453.5 & 46383.5 & 6600.7 & \\
\hline 2020 & & 6935.5 & 44566.6 & 38942.5 & 43784.5 & 1301.8 & 39734.4 & 46723.9 & 6880.1 & \\
\hline 2020.5 & & & 44470.4 & 39176.9 & & 1315.6 & 40450.9 & 47064.3 & 7064.5 & \\
\hline 2021 & & & 44733.5 & 39469.9 & & 1356.2 & 41167.4 & 47611.7 & 7248.8 & \\
\hline 2021.5 & & & 44996.6 & 39762.9 & & 1396.9 & 41537.9 & 48159.1 & 6966.3 & \\
\hline 2022 & & & 45163.5 & 39667.3 & & 1440.8 & 41908.4 & 48470.5 & 6683.8 & \\
\hline 2022.5 & & & 45330.4 & 39571.6 & & 1484.7 & 41936.6 & 48781.9 & 6822.5 & \\
\hline 2023 & & & 46195.5 & & & 1541.7 & 41964.9 & 49198.1 & 6961.3 & \\
\hline 2023.5 & & & 47060.6 & & & 1598.8 & 41792.3 & 49614.3 & 7096.2 & \\
\hline 2024 & & & 47862.4 & & & 1660.5 & 41619.6 & 50155.2 & 7231.0 & \\
\hline 2024.5 & & & 48664.1 & & & 1722.2 & 41772.1 & 50696.1 & 7340.5 & \\
\hline 2025 & & & 48974.5 & & & 1793.7 & 41924.6 & 50445.2 & 7450.1 & \\
\hline 2025.5 & & & 49284.9 & & & 1865.2 & 41964.0 & 50194.3 & & \\
\hline 2026 & & & 48076.2 & & & 1888.7 & 42003.3 & 48834.3 & & \\
\hline 2026.5 & & & 46867.5 & & & 1912.1 & 42343.4 & 47474.4 & & \\
\hline 2027 & & & 47845.1 & & & 1979.7 & 42683.4 & 48599.6 & & \\
\hline 2027.5 & & & 48822.8 & & & 2047.3 & 42884.0 & 49724.8 & & \\
\hline 2028 & & & 49630.1 & & & 2137.8 & 43084.7 & 49512.1 & & \\
\hline 2028.5 & & & 50437.4 & & & 2228.3 & 42673.0 & 49299.3 & & \\
\hline 2029 & & & 51044.2 & & & 2287.2 & 42261.3 & 49832.0 & & \\
\hline 2029.5 & & & 51651.0 & & & 2346.0 & 40980.7 & 50364.7 & & \\
\hline 2030 & & & & & & 2386.2 & 39700.1 & & & \\
\hline 2030.5 & & & & & & 2426.3 & 39945.1 & & & \\
\hline 2031 & & & & & & & 40190.2 & & & \\
\hline 2031.5 & & & & & & & 40206.2 & & & \\
\hline 2032 & & & & & & & 40222.2 & & & \\
\hline 2032.5 & & & & & & & 40102.5 & & & \\
\hline 2033 & & & & & & & 39982.8 & & & \\
\hline
\end{tabular}

country. Table 2 depicts the values for the set $\$ f 10$ countries. Since prediction reflects the past we avoid those typical and unrealistic smooth curves. Winston Churchill said "The longer you can look back, the farther you can look forward".

\section{Conclusions}

This paper proposed a novel method for analysing the dynamics a country economies. From the mathematical perspective the method is based on the PPP processing of the time series having in mind the long range modeling capabilities of FC.

Mathematical methods do not consider possible institutional adjustments (such as the end of the European Union, or the segregation of partners having slower growth paths). In the same way, they cannot predict political decisions on military conflicts, although close levels of prosperity combined with territorial continuities can explain conflicts in the historical past [48]. From this perspective, coalitions among BRICs may represent neighboring threat.

From the economic point of view we can say that by 2020 the global ranking will be not so different from what it is nowadays. USA will lead the leather. However, two European countries (Germany and Great Britain), and Japan, will be closer to USA. Curiously, France is now close to Germany and Great Britain, but its divergent path will make it more similar to Italy, in 2020, than to Germany and Great Britain. This means that USA will go on at the top position, followed by Germany and Great Britain. Behind this group, France and Italy will follow up. Clearly in a recovery period, "this optimism can now be seen in the US economy [where] corporate leaders (.. .) feel more hopeful about their prospects than they have in years" [49]. Such a last phase also expresses Western lifestyles convergence, confirming Rostow [9]. 
Among the BRICs changes in relative positions will occur in a much clearer way: nowadays the Brazilian GDP per capita is much above the Chinese but behind the Russian, while India is on the tail. However, distances among Brazil, Russia and China will be almost canceled, and the three BRC will make a pool of competitors. "Overall economic growth and development of financial markets allowed even the poorest Russian regions to grow out of poverty traps" [50], while growth expectations for Brazil proceed at a slower pace and "we (.. .) expect 8.2\% growth from China, which is hardly anaemic" [49], in the context of recent Chinese growth rates. By 2020 India will go on as a tail. As Battisti et al. says, "Although a country converges to its long-run growth path, this path can diverge from the countries at the global frontier" [51].

According to forecasts, 2030 will be a global turning point. Germany will catch up Japan. The two WWII defeated nations will be ahead of Italy. According to the PPP methodology, India will not catch-up, in spite of benefiting from stronger external demand in advanced economies and China, and fast dynamics. The low levels of departure do matter.

In a distinct level, the proposed mathematical approach of exploring the common use of PPP and FC produced a new perspective in the modeling of the dynamics of country economies and pointed out possibilities for estimating the future trends of the time series.

\section{References}

[1] Korotayev AV, Tsirel SV. A spectral analysis of world GDP dynamics: kondratieff waves, kuznets swings, juglar and kitchin cycles in global economic development, and the 2008-2009 economic crisis. Struct Dyn 2010;4(1):1-55.

[2] Fogel RW. Capitalism and democracy in 2040: forecasts and speculations, NBER working-paper no. 13184; National bureau of economic research; 2007. URL: <http://www.nber.org/papers/w13184>.

[3] Bordo M, Eichengreen B, Klingebiel D, Martinez-Peria MS, Rose AK. Is the crisis problem growing more severe? Econ Policy 2001;16(32):53-82.

[4] Schularick M, Taylor AM. Credit booms gone bust: monetary policy, leverage cycles and financial crises, 1870-2008. Am Econ Rev 2012;102(2):1029-61.

[5] Taylor AM. The great leveraging, NBER working-paper no. 18290; National bureau of economic research; 2012.

[6] Maito EE. The historical transience of capital: the downward trend in the rate of profit since XIX century, MPRA paper no. 55894; National bureau of economic research; 2014.

[7] Schumpeter JA. Business cycles, a theoretical, historical and statistical analysis of the capitalist process. New York: Martino Pub; 1939.

[8] Hayek FA. The road to serfdom: with the intellectuals and socialism. London: Routledge; 1944.

[9] Rostow WW. Stages of economic growth, a non-communist manifesto. Cambridge: Cambridge University Press; 1960.

[10] Machado JAT, Mata ME. A multidimensional scaling perspective of Rostows forecasts with the track-record (1960s-2011) of pioneers and latecomers. In: Awrejcewicz J, Kazmierczak M, Olejnik P, Mrozowski J, editors. Dynamical systems: theory, proceedings of the 12th international conference on dynamical systems theory and applications. Poland: Lódź; 2013. p. 361-78.

[11] Machado JAT, Mata ME. Multidimensional scaling analysis of the dynamics of a country economy. Sci World J 2013;2013:15. http://dx.doi.org/ 10.1155/2013/594587 (Article ID 594587).

[12] Takens F. Detecting strange attractors in turbulence. In: Rand D, Young L-S, editors. Dynamical systems and turbulence, proceedings of a symposium held at the university of Warwick 1979/80. Lecture notes in mathematics, vol. 898. Berlin, Germany: Springer; 1981. p. 366-81.

[13] Duarte FB, Machado JAT, Duarte GM. Dynamics of the Dow Jones and the NASDAQ stock indexes. Nonlinear Dyn 2010;61(4):691-705.

[14] Lima MFM, Machado JAT. Fractional dynamics representation in the pseudo phase plane. Acta Mec Sin 2011;27(1):28-35.

[15] Lopes AM, Machado JAT. Dynamic analysis of earthquake phenomena by means of pseudo phase plane. Nonlinear Dyn 2013;74(4):1191-202.

[16] Ionescu CM, Machado JT, Keyser RD. Analysis of the respiratory dynamics during normal breathing by means of pseudo phase plots and pressurevolume loops. IEEE Trans Syst Man Cybern: Syst 2013;43(1):53-62.

[17] Machado JAT, Lopes AM. Complex dynamics of forest fires. Math Prob Eng 2014;2014:8 (Article ID 575872).

[18] Oldham K, Spanier J. The fractional calculus: theory and application of differentiation and integration to arbitrary order. New York: Academic Press; 1974.

[19] Miller K, Ross B. An introduction to the fractional calculus and fractional differential equations. New York: John Wiley and Sons; 1993.

[20] Samko S, Kilbas A, Marichev O. Fractional integrals and derivatives: theory and applications. Amsterdam: Gordon and Breach Science Publishers; 1993.

[21] Podlubny I. Fractional differential equations. An introduction to fractional derivatives, fractional differential equations, to methods of their solution, mathematics in science and engineering, vol. 198. San Diego: Academic Press; 1998.

[22] Kilbas A, Srivastava H, Trujillo J. Theory and applications of fractional differential equations. North-Holland Mathematics Studies, vol. 204. Amsterdam: Elsevier; 2006.

[23] Oustaloup A. Systèmes asservis linéaires d'ordre fractionnaire: théorie et pratique. Paris: Masson; 1983.

[24] Machado JT. Analysis and design of fractional-order digital control systems. Syst Anal Model Simul 1997;27(2-3):107-22.

[25] Hilfer R. Application of fractional calculus in physics. Singapore: World Scientific; 2000.

[26] Zaslavsky G. Hamiltonian chaos and fractional dynamics. Oxford: Oxford University Press; 2005.

[27] Sabatier J, Agrawal OP, Machado JT. Advances in fractional calculus: theoretical developments and applications in physics and engineering. Dordrecht, The Netherlands: Springer; 2007.

[28] Tarasov V. Fractional dynamics: applications of fractional calculus to dynamics of particles, fields and media. New York: Springer; 2010.

[29] Mainardi F. Fractional calculus and waves in linear viscoelasticity: an introduction to mathematical models. London: Imperial College Press; 2010.

[30] Petráš I. Fractional-order nonlinear systems: modeling, analysis and simulation. Heidelberg: Springer; 2011.

[31] Baleanu D, Diethelm K, Scalas E, Trujillo JJ. Fractional calculus: models and numerical methods. Series on complexity, nonlinearity and chaos. Singapore: World Scientific Publishing Company; 2012.

[32] Ionescu C. The human respiratory system: an analysis of the interplay between anatomy, structure, breathing and fractal dynamics. Series in BioEngineering. London: Springer-Verlag; 2013.

[33] Machado JAT, Stefanescu P, Tintareanu O, Baleanu D. Fractional calculus analysis of the cosmic microwave background. Rom. Rep. Phys. 2013;65(1):316-23.

[34] Wang L-F, Yang X-J, Baleanu D, Cattani C, Zhao Y. Fractal dynamical model of vehicular traffic flow within the local fractional conservation laws. Abstr Appl Anal 2014;2014:5 (Article ID 635760).

[35] Razminia A, Baleanu D. Fractional order models of industrial pneumatic controllers. Abstr Appl Anal 2014;2014:9 (Article ID 871614).

[36] Wu G-C, Baleanu D. Discrete fractional logistic map and its chaos. Nonlinear Dyn 2014;75(1-2):283-7.

[37] Scalas E, Gorenflo R, Mainardi F. Fractional calculus and continuous-time finance. Phys A: Stat Mech Appl 2000;284(1-4):376-84.

[38] Mainardi F, Raberto M, Gorenflo R, Scalas E. Fractional calculus and continuous-time finance II: the waiting-time distribution. Phys A: Stat Mech Appl 2000;287(3-4):468-81.

[39] Scalas E, Gorenflo R, Mainardi F. Waiting-times and returns in high-frequency financial data: an empirical study. Phys A: Stat Mech Appl 2002;314(14):749-55. 
[40] Machado JAT, Mata ME. A fractional perspective to the bond graph modelling of world economies. Nonlinear Dyn; http://dx.doi.org/10.1007/s11071014-1334-0.

[41] Valério D, Trujillo JJ, Rivero M, Machado JT, Baleanu D. Fractional calculus: a survey of useful formulas. Eur Phys J Spec Top 2013;222(8):1827-46.

[42] Podlubny I. Fractional-order systems and $\mathrm{PI}^{k} \mathrm{D}^{l}$-controllers. IEEE Trans Autom Control 1999;44(1):208-13.

[43] Chen Y, Moore K. Discretization schemes for fractional-order differentiators and integrators. IEEE Trans Circuits Syst - I: Fund Theory Appl 2002;49(3):363-7.

[44] Machado JAT. Fractional derivatives: probability interpretation and frequency response of rational approximations. Commun Nonlinear Sci Numer Simul 2009;14(9-10):3492-7.

[45] Machado JAT. Calculation of fractional derivatives of noisy data with genetic algorithms. Nonlinear Dyn 2009;57(1-2):253-60.

[46] Deza MM, Deza E. Encyclopedia of distances. Berlin, Heidelberg: Springer-Verlag; 2009.

[47] di Giovanni J, Levchenko AA, Zhang J. The global welfare impact of China: trade integration and technological change. CEPR discussion paper; Centre for Economic Policy Research; 2013. URL: <http://www.cepr.org/pubs/new-dps/dplist.php?dpno=109683>.

[48] Milward AS. War, economy, and society, 1939-45. London: Penguin; 1987.

[49] Stovsky R, Esch K. Trendsetter barometer: business outlook, Tech. rep., PricewaterhouseCoopers LLP; 2014. URL: <http://www.pwc.com/enUS/us/ privatecompany-services/publications/assets/pwc-trendsetter-barometer-q1-2014.pdf>.

[50] Guriev S, Vakulenko E. Breaking out of poverty traps: internal migration and interregional convergence in Russia, DP9675; Center for Economic Policy Research; 2013. URL: <http://www.cepr.org/pubs/dps/DP9675>

[51] Battisti M, di Vaio G, Zeira J. Global divergence in growth regressions center for economic policy research. DP96872013, Center for Economic Policy Research; 2013. URL: <http://www.cepr.org/pubs/dps/DP9687>. 